\title{
Improved Biodegradable Radiation Cured Polymeric Film Prepared from Chitosan-Gelatin Blend
}

\author{
Zinia Nasreen, ${ }^{1}$ Mubarak A. Khan, ${ }^{2}$ and A. I. Mustafa ${ }^{3}$ \\ ${ }^{1}$ Department of Chemistry, Dhaka University of Engineering and Technology, Gazipur 1700, Bangladesh \\ ${ }^{2}$ Radiation and Polymer Chemistry Laboratory, Institute of Nuclear Science and Technology, Bangladesh Atomic Energy Commission, \\ P.O. Box 3787, Dhaka 1000, Bangladesh \\ ${ }^{3}$ Department of Applied Chemistry and Chemical Engineering, University of Dhaka, Dhaka 1000, Bangladesh
}

Correspondence should be addressed to Zinia Nasreen; zinia@duet.ac.bd

Received 27 October 2015; Revised 13 December 2015; Accepted 15 December 2015

Academic Editor: Marcel Popa

Copyright (c) 2016 Zinia Nasreen et al. This is an open access article distributed under the Creative Commons Attribution License, which permits unrestricted use, distribution, and reproduction in any medium, provided the original work is properly cited.

The mechanical, thermal, swelling, and release properties of chitosan-gelatin (CG) films have been investigated in order to verify the influence of UV and gamma radiation on the stability of the films. Thin films of chitosan and gelatin $(1: 3, \mathrm{w} / \mathrm{w})$ that were radiated with $100 \mathrm{krad}$ of gamma dose showed the best performance and the TS values reached 25, 45, and $49 \mathrm{MPa}$, respectively, for chitosan, gelatin, and blend. The corresponding highest TS values were 23,42 , and $45 \mathrm{MPa}$, respectively, for 10 passes of UV radiation. The effect of radiation over gelatin, chitosan, and CG blend caused modification in the arrangement of molecules in the crystal lattice that is significant by XRD analysis. Surfaces of the films were also investigated by scanning electron microscope (SEM). Fourier transform infrared spectroscopy (FTIR) studies further revealed structural changes of the films. These changes were attributed to understanding the behavior of the irradiated chitosan, gelatin, and CG blend on application of thermal energy using DSC and TGA studies, water uptake of the films in aqueous medium, and soil degradation properties to observe the best possibility for its application.

\section{Introduction}

Biopolymers attract a significant attention to the scientists because they are abundantly found worldwide. Most of the biopolymers can be used as biomaterial. Chitosan and gelatin are natural biopolymers and have the film forming properties [1-4]. Extensive research works are going on chitosan and also its property modifications for suitable applications. It is now matured that chitosan can suitably be applied in biomedical, pharmaceutical, and agricultural applications [5-7]. Chitosan is 2 -amino-2-deoxy- $\beta$-D-glucose unit. The advantage of chitosan is its biodegradability and its antibacterial activity. It is reported that chitosan grafted copolymer nanoparticles were obtained by free radical polymerization with different comonomers; these new polymers allow encapsulation of proteins and sustained drug release [8-10].

Gelatin is a hydrocolloid natural biopolymer. It dissolves in hot distilled water and forms jelly when cooled. Gelatin is obtained by partial hydrolysis of collagen derived from natural sources such as skin, connective tissue, and bones of animals involving denaturation and physical and chemical degradation. Gelatin is a protein derivative obtained by boiling collagen. Commercial gelatin is a vitreous solid having a faint yellow color. The uses of gelatin depend on its characteristic properties. Its proteinaceous nature makes it used in food, abrasive, gummed tape, and adhesives and also as a protective colloid for the prevention of coalescence [11-15]. On the other hand, gelatin is widely utilized in the manufacture of various articles and materials as it is a polymeric material. The number and the variety of reactive groups along the chain enhance the possibilities of modifying gelatin using various potential reagents. Addition of monomers to gelatin was found to be similar to vinyl polymerization to give an extended carbon chain attached to the side group of the gelatin molecules. Blends of biopolymer with common polymers are of great significance for expanding application to biochemical and biodegradable materials $[10,16-$ 18]. Gelatin is biodegradable and has good biocompatibility, 
which makes it used as tissue replacement material. Chitosan was graft copolymerized to enhance the property and also combined with gelatin to be used as wound dressing materials. Permanent cross-linking of gelatin can be achieved by reaction with aldehydes such as formaldehyde, glyoxal, or glutaraldehyde [19-21]. Chitosan-gelatin surgical wound dressing is a kind of excellent wound healing material. In order to testify the safe reliability, antibacterial property, and wound healing ability, a lot of experiments were executed. The results showed its safe reliability and good antibacterial property. The film casting solution including pectin and gelatin was irradiated at $0,10,20$, and $30 \mathrm{KGY}$ to investigate the irradiation effect on the mechanical properties of the film and tensile strength of the $10 \mathrm{KGY}$ irradiated film was the highest among the treatments.

Aqueous solutions of carboxymethylated chitosan (CM chitosan) were radiated with $\gamma$-ray in various conditions. The radiation chemical yields of CM chitosan degradation were found to decrease at lower $\mathrm{pH}$ in which the polymer chains tend to coiled conformation. FTIR and UV spectra showed that main chain structures of CM chitosan remained and some carbonyl/carbonyl groups were formed during the degradation.

Use of UV radiation source has some advantages like low energy consumption, ambient temperature operations, no emission of solvents, reduced reaction time, enhanced product quality, and so forth [22]. Photo-initiated graft polymerization is one of the fasted and most efficient methods to improve physicomechanical properties of natural polymers. UV radiation is weak type of nonionizing radiation source [23]. The application of gamma radiation is increasing. Over the past few decades there has been a continuous and significant growth in the development and application of radiation techniques, primarily in coating and adhesive industry. As this technique continues to develop innovative new products based on high efficiency and easy process control a logical extension for this technology is in the field of composite materials. The use of gamma radiation to natural biopolymers offers several advantages, such as continuous operation, minimum time requirement, less atmospheric pollution, curing at ambient temperature, and increased design flexibility through process control $[9,24]$. The aim of the present investigation was to prepare and characterize thin films of chitosan, gelatin, and their blends. The effect of gamma and UV radiations on the mechanical and thermal properties of the prepared films was also found out.

\section{Experimental}

2.1. Materials. Pharmaceutical grade gelatin (bloom number 185) was collected from Global Capsules Ltd., Barisal, Bangladesh. Chitosan was extracted from Prawn (Penaeus monodon) shell [8]. Sodium hydroxide $(\mathrm{NaOH})$, hydrochloric acid $(\mathrm{HCl})$, and ethanoic acid $\left(\mathrm{CH}_{3} \mathrm{COOH}\right)$ were supplied by Merck, Germany.

2.2. Preparation of Thin Film of Chitosan, Gelatin, and Blends. $2 \%$ percent chitosan solution $(\mathrm{w} / \mathrm{w})$ was prepared in aqueous solution of acetic acid (2\%). The films of chitosan (thickness was about $0.1 \mathrm{~mm}$ ) were made by casting. The dried films were preserved in polyethylene bags and stored in desiccators for further analysis. Gelatin films were also prepared by casting from its aqueous solution using $2 \%$ gelatin solution. For the preparation of blend (chitosan and gelatin ratio was $1: 3 \mathrm{w} / \mathrm{w}$ ) gelatin was dissolved in hot water by continuous stirring with magnetic stirrer for about an hour; then aqueous chitosan solution was mixed and properly stirred [25]. The solution was cast onto the silicon cloth frames mounted on flat glass plate for film formation and dried in an oven at $70^{\circ} \mathrm{C}$ for 12 hours. The dried films (about $0.20 \mathrm{~mm}$ thickness) thus prepared were peeled off and cut into small pieces for further tests.

2.3. Use of Gamma Irradiation. Films of chitosan, gelatin, and blend were irradiated using a Co-60 Gamma source (25 kci) of the Bangladesh Atomic Energy Commission (BAEC), Saver, Dhaka. Dose rate was $350 \mathrm{krad} /$ hour.

2.4. UV Curing of the Films. Samples were irradiated under a UV lamp (254-313 nm, model UV-200, 1ST-Technik, Germany) with $2 \mathrm{~kW}$ power capacity at various intensities expressed in number of passes. The conveyor speed of the UV manicure was $4 \mathrm{~m} / \mathrm{min}$. The samples were subjected to various characterization processes after 24 hours of radiation.

2.5. Mechanical Tests of the Films. Tensile strength (TS), tensile modulus (TM), and elongation at break (Eb\%) of the film samples were determined using a universal testing machine (Houston $\mathrm{S}$ testing series, UK). The load range was $500 \mathrm{~N}$ with $10 \mathrm{~mm} / \mathrm{min}$ crosshead speed and $20 \mathrm{~mm}$ gauge length. All the results were taken as the average values of 6 samples. Relative humidity was at least $65 \%$.

2.6. Water Uptake of the Films. Film samples were immersed in the static water beaker at $25^{\circ} \mathrm{C}$ for different time periods (10-90 seconds). Before immersion in the water, the weight of the samples was measured. After certain period of time, samples were taken out from the beaker, wiped using tissue papers, and then weighed again. The water uptake (mass gained) was calculated by the subtraction of initial weight from the final weight.

2.7. Thermal Analysis. The thermal test of the films was taken using computer controlled TG/DTA 6300 system controlled to an EXSTAR 6000 STATION, Seiko Instrument, Inc., Japan. The TG/DTA module uses a horizontal system balance mechanism. All the experiments were performed in the nitrogen atmosphere. Samples weights were $10-15 \mathrm{mg}$, and heating rate was $10^{\circ} \mathrm{C} / \mathrm{min}$.

2.8. X-Ray Diffraction Studies. A PHILIPS PW3040 Pert PRO $\mathrm{X}$-Ray Diffractometer was used. The films were exposed to $\mathrm{CuK}_{\alpha}$ radiation with a primary beam of $40 \mathrm{kV}$ and $30 \mathrm{~mA}$ with a sampling pitch of $0.02^{\circ}$ and time for each step data collection was $0.1 \mathrm{sec}$. A $2 \theta$ scan was taken from $15^{\circ}$ to $35^{\circ}$ to get possible fundamental peaks where Ni filter was used 
TABLE 1: Mechanical properties of the thin films of chitosan, gelatin, and blend.

\begin{tabular}{lccc}
\hline Film & $\begin{array}{c}\text { Tensile } \\
\text { strength } \\
(\mathrm{MPa})\end{array}$ & $\begin{array}{c}\text { Tensile } \\
\text { modulus } \\
(\mathrm{MPa})\end{array}$ & $\begin{array}{c}\text { Elongation at } \\
\text { break (\%) }\end{array}$ \\
\hline Chitosan & $18 \pm 0.5$ & $445 \pm 35$ & $10 \pm 1$ \\
Gelatin & $39 \pm 0.8$ & $656 \pm 44$ & $6 \pm 0.4$ \\
Blend & $43 \pm 1$ & $782 \pm 40$ & $18 \pm 1.5$ \\
\hline
\end{tabular}

to reduce $\mathrm{CuK}_{\beta}$ radiation. All the data of the samples were analyzed using computer software "X'PERT HIGHSCOPE." The integrated intensity of the blend films was investigated by using the following equation:

$$
\begin{aligned}
& \text { Integrated Intensity }(I) \\
& \quad=\text { Peak Height }(h) \times \text { FWHM, }
\end{aligned}
$$

where FWHM is Full Width at Half Maximum.

2.9. Fourier Transform Infrared Spectroscopy (FTIR). The FTIR spectroscopy of chitosan-gelatin blend films was performed by FTIR Spectrophotometer (Paragon 500 Model, PerkinElmer, Beaconsfield, Buckinghamshire, UK) in the wave number range $400-3500 \mathrm{~cm}^{-1}$ with resolution of $4 \mathrm{~cm}^{-1}$. The FTIR spectrum was taken in a transmittance mode.

2.10. Scanning Electron Microscopic (SEM) Study. The morphological study of the chitosan-gelatin blend film was done using a JEOL 6400 SEM at an accelerating voltage of $10 \mathrm{kV}$. The SEM specimens were sputter-coated with gold.

\section{Results and Discussion}

3.1. Mechanical Properties of the Films of Chitosan, Gelatin, and Blend. Thin films of chitosan, gelatin, and a blend of chitosan and gelatin $(1: 3, \mathrm{w} / \mathrm{w})$ were prepared by casting. Tensile strength (TS), tensile modulus (TM), and percent elongation at break (Eb\%) were evaluated and are given in Table 1. It was found that TS, TM, and Eb of the blend are higher than those of the chitosan or gelatin films. The TS of the blend film was found to be $43 \mathrm{MPa}$, that is, 139 and $10 \%$ higher over chitosan and gelatin films, respectively [26].

3.2. Effect of Gamma Radiation on the Films of Chitosan, Gelatin, and Their Blend. Thin films of chitosan, gelatin, and blend were exposed to gamma radiation varying total doses at a rate of $350 \mathrm{krad} /$ hour to find out the effect of gamma radiation on the films. Tensile strength (TS), tensile modulus (TM), and percent elongation at break (Eb\%) of the films were evaluated. The results are presented in Figures 1-3. The results of TS values for the films of chitosan, gelatin, and blend against total gamma dose are shown in Figure 1. It was found that, at $25 \mathrm{krad}$ of total dose, TS of chitosan, gelatin, and blend was decreased and then moved upward and the highest values of TS were found at $100 \mathrm{krad}$. After $100 \mathrm{krad}$, TS was found to

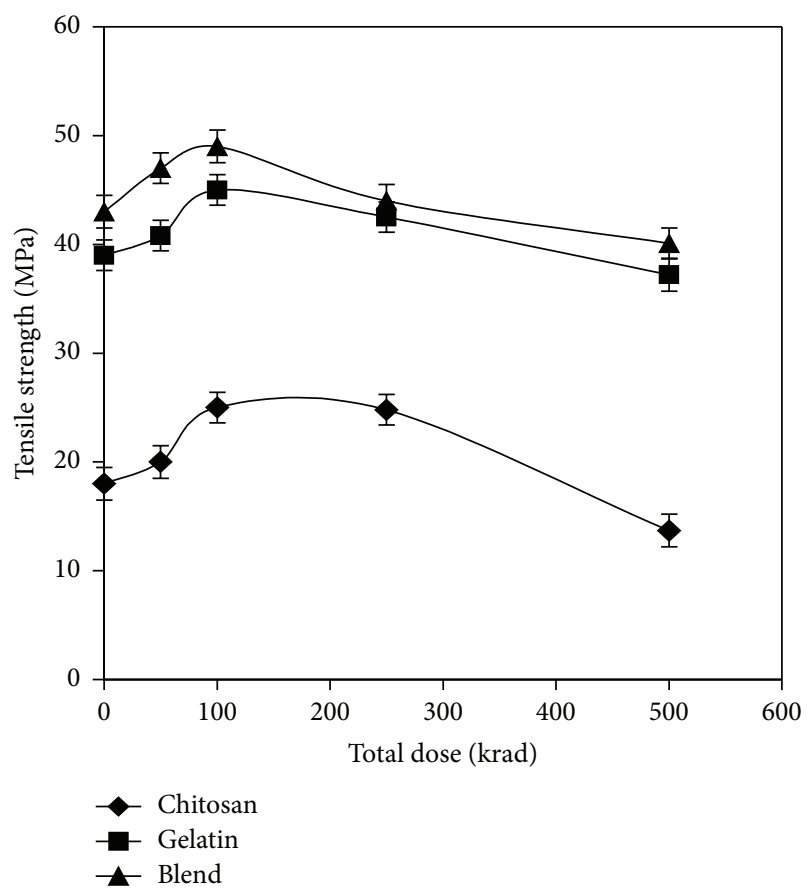

FIGURE 1: Tensile strength against gamma radiation dose (krad) for chitosan, gelatin, and blend.

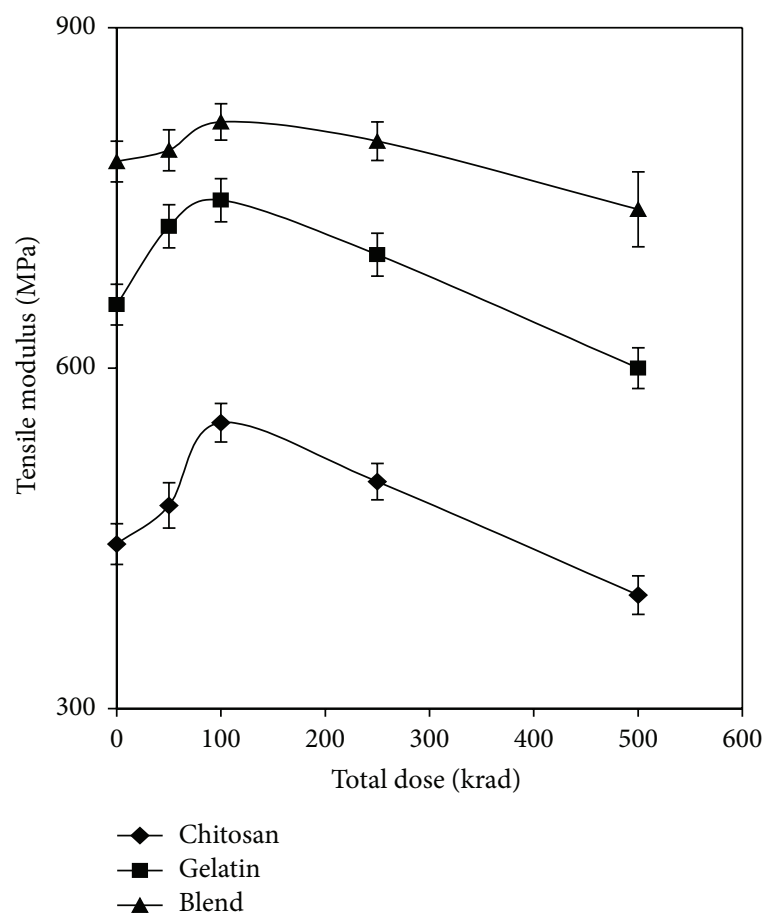

FIgURE 2: Tensile modulus against gamma radiation dose (krad) for chitosan, gelatin, and blend.

decrease slowly and at $500 \mathrm{krad}$ of total dose, TS decreased more than that of the original values. From this investigation it is clearly found that gamma radiation has a strong effect on chitosan, gelatin, and their blend. It can be concluded that, at $100 \mathrm{krad}$ of exposure of gamma radiation, chitosan, gelatin, 


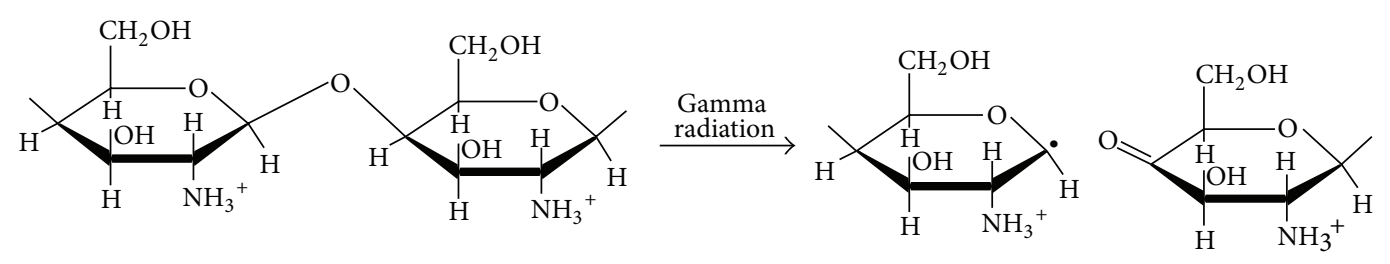

Scheme 1: Degradation mechanism of chitosan under gamma source.

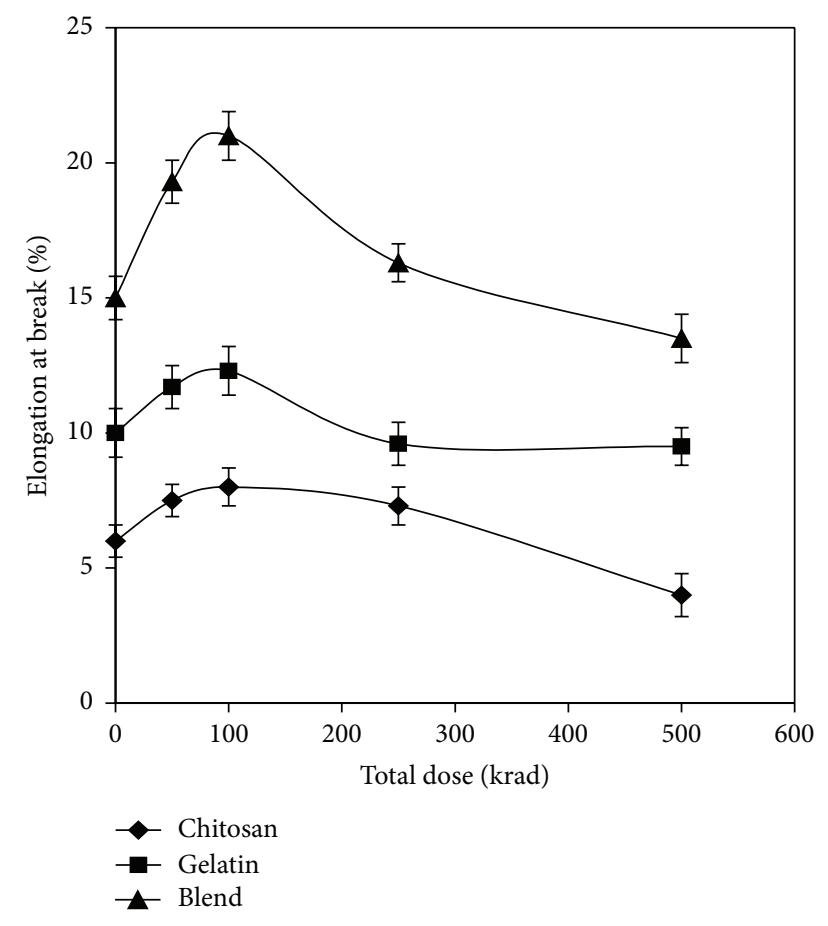

FIGURE 3: Elongation at break against gamma radiation dose for chitosan, gelatin, and blend.

and blend gained 39,15 , and $14 \%$ increment of TS over their nonirradiated counterparts (Figure 15).

In Figure 2, tensile modulus (TM) is plotted against gamma radiation dose of the films of chitosan, gelatin, and their blend. Almost similar results were found like TS of the films of chitosan, gelatin, and blend that is explained above. At low dose (25 krad), TM was decreased and after that TM increased and we found the highest values at $100 \mathrm{krad}$. High (500 krad) gamma dose caused low TM values of all the films. Figure 3 explains the elongation at break against gamma radiation dose for the films of chitosan, gelatin, and blend. This result indicated that at $100 \mathrm{krad}$ of total dose onto the films $\mathrm{Eb}(\%)$ values decreased and then moved upward. These findings supported the results for TS and TM of the films of chitosan, gelatin, and blend. From the above discussion, it is quite clear that, at $100 \mathrm{krad}$ of total dose, TS and TM increased but Eb decreased because, at this dose, films became strong and elongation became low, as expected. Actually gamma radiation can play a significant role for the modification of polymers. Gamma radiation is ionizing radiation and has strong effect on natural polymers [27]. Use of gamma radiation is attributed to higher mechanical properties; gamma radiation produces three types of reactive species in polymer (chitosan, gelatin) (Schemes 1 and 2). These are ionic, radical, and peroxide species. The peroxide species are produced because the polymers were irradiated in presence of oxygen. When chitosan or gelatin or blend is subjected to gamma radiation, some radicals are produced. Gamma radiation also ruptures some carbon-carbon bonds and produces radicals. Chain scission may also take place to form other radicals. Cross-linking and chain scission occurred when polymers are exposed to gamma radiation. Polysaccharides and other natural polymers generally degrade by breaking of glycosidic linkage under gamma radiation. Gelatin is natural biopolymer that consists of protein molecules which can easily fragment due to gamma radiation. The nature of gelatin chain scission is like where some of the free radicals generated. The generated free radicals may cross-link each other and form more cross-linked gelatin molecules with the exposure of gamma ray; as a result tensile properties might be increased. It is reported in the literature that chitosan molecules also form free radicals in a similar nature when irradiated to gamma radiation.

3.3. Effect of UV Radiation on the Films of Chitosan, Gelatin, and Their Blend. To investigate the effect of UV radiation on chitosan and gelatin, thus films were exposed to the UV source. The films of chitosan, gelatin, and their blend were treated with UV radiation varying intensities. The UV radiation source was conveyor type and the intensity is termed as the number of UV passes. One pass of UV indicated that the sample was exposed to UV under $60 \mathrm{~cm}$ length of conveyor belt. The details of the UV source are mentioned in the experimental section. Tensile strength (TS), tensile modulus (TM), and percent elongation at break (Eb\%) of the films of chitosan, gelatin, and blend were evaluated by universal testing machine. The results are presented in Figures 4-6. The results of TS values for the films of chitosan, gelatin, and blend against UV radiation intensities (termed as the number of passes) are shown in Figure 4. It was found that, at 5 passes of UV, TS of the films of chitosan, gelatin, and blend slightly decreased and then moved upward; the highest values of TS were found at 10 passes of UV. It was also noticed that TS was again decreased slowly at 25 passes of UV dose. At 25 passes, TS was found to decrease more than that of the original values. From this investigation it is clearly found that UV radiation has a weak effect on chitosan, gelatin, and their blend. It can be concluded that, at 


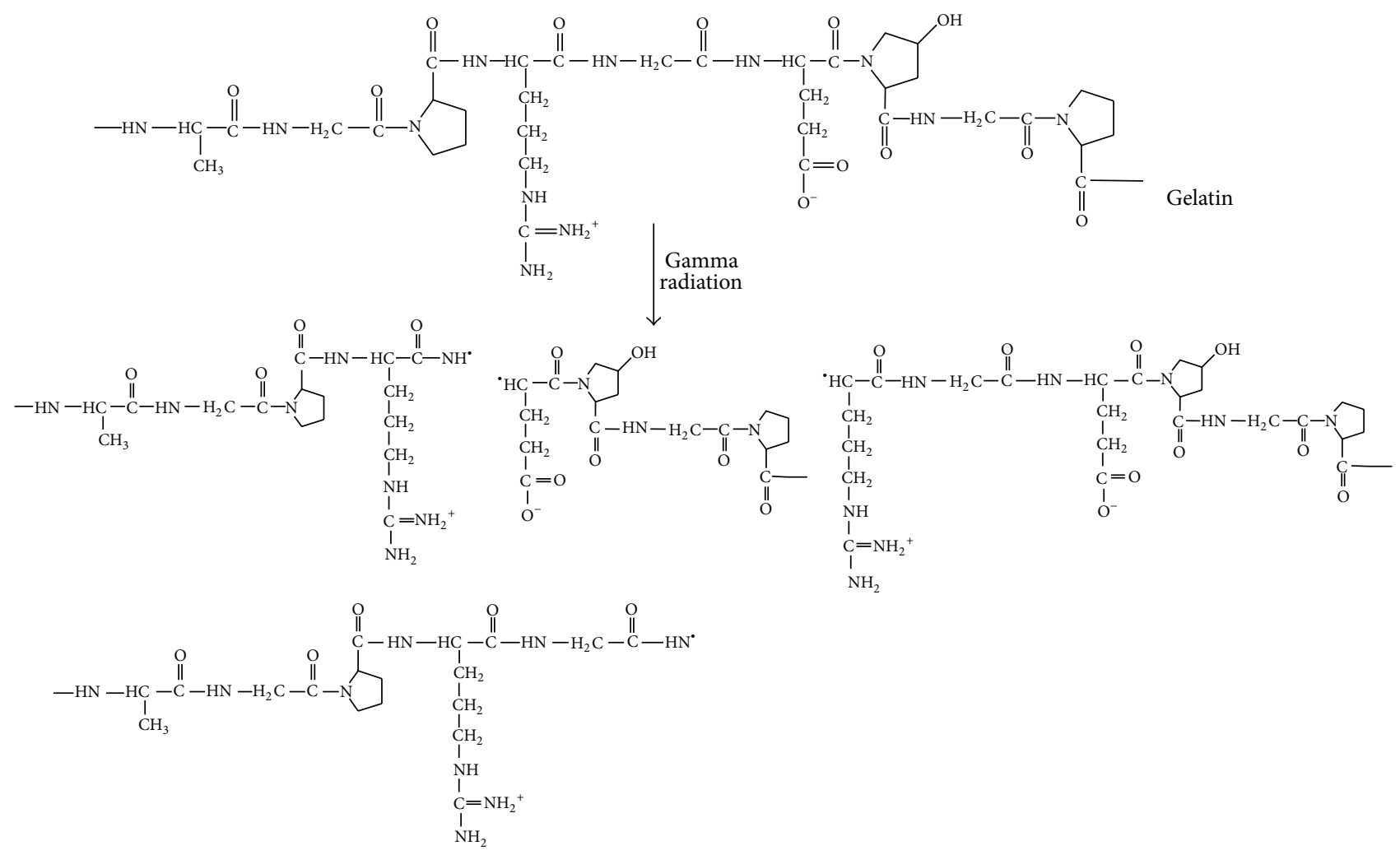

Scheme 2: Degradation mechanism of gelatin under gamma source.

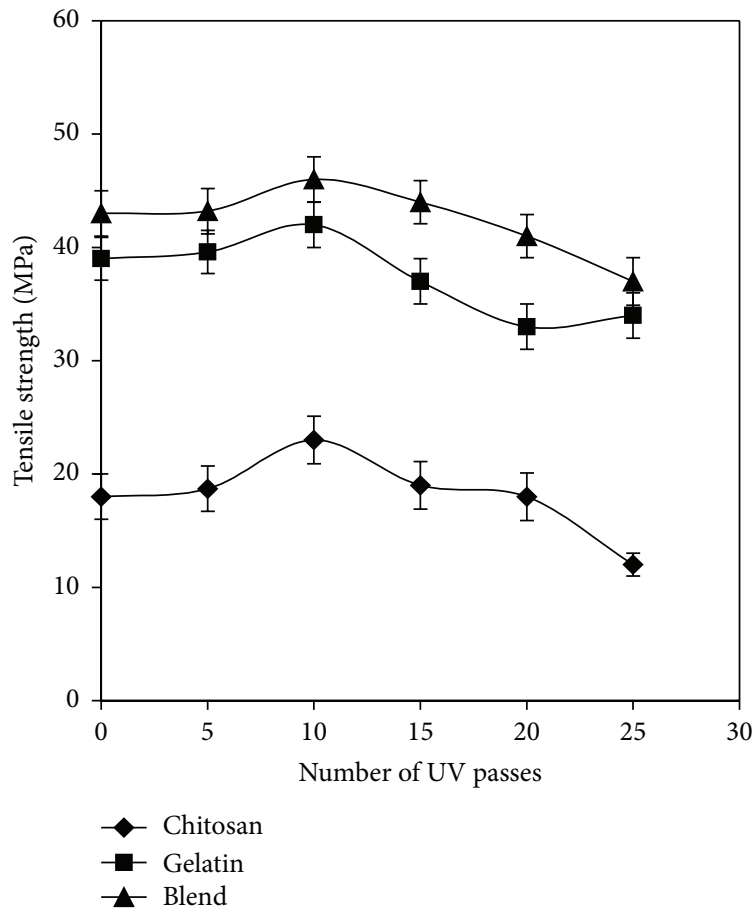

FIGURE 4: Tensile strength versus number of UV passes for chitosan, gelatin, and blend.

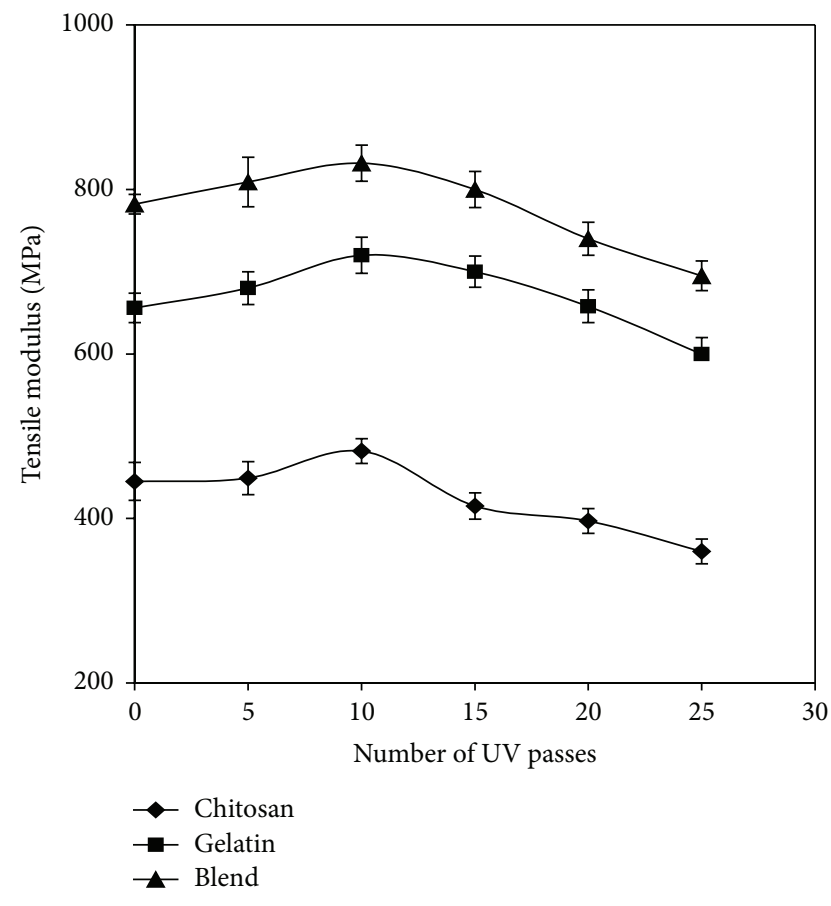

FIgURE 5: Tensile modulus versus number of UV passes for chitosan, gelatin, and blend. 


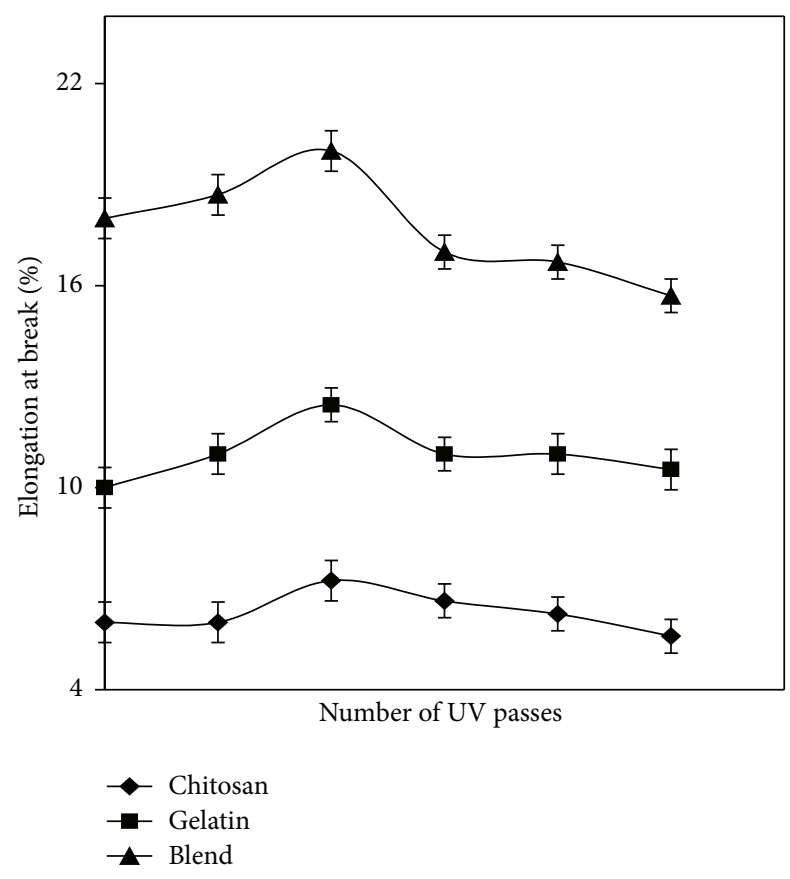

FIGURE 6: Elongation at break versus number of UV passes for gelatin, chitosan, and blends.

10 passes of UV radiation, chitosan, gelatin, and blend gained $28,7.6$, and $4.6 \%$ increment of TS over their nonirradiated counterparts. The effect of UV radiation on the TM of the films of chitosan, gelatin, and blend was studied and the results are depicted in Figure 5. It was found that, at 5 passes of UV, TM of the films decreased slightly but after that dose, TM gradually increased and the highest TM was observed at 10 passes of UV. At higher dose of UV, TM decreased again. Elongation at break $(\mathrm{Eb} \%)$ of the chitosan, gelatin, and blend versus number of UV passes is presented in Figure 6. This figure represents that, at 5 passes of $\mathrm{UV}, \mathrm{Eb} \%$ increased and after that dose it decreased and the nature is quite similar to that mentioned in Figure 3. TS and TM increase with increasing irradiation doses up to a certain limit but after that, they decrease due to opposite phenomenon such as photo cross-linking and photodegradation that were taking place simultaneously under UV radiation. In lower dose, free radicals are stabilized by combination reactions; as a result, photo cross-linking or intercross-linking occurs between the neighboring polymeric molecules. The higher is the number of active sites generated on the polymeric substrate, the greater is the cross-linking efficiency. At higher UV radiation (above 10 passes), TS and TM values decrease, which may be associated with the photodegradation of polymer backbone at higher UV does. At higher radiation, main chain may be broken and polymer may degrade into fragments. As a result, tensile properties decreased with increasing higher UV doses. During photodegradation, there will be loss in strength due to primary bond breakage in the polymer constituents [28, 29].

3.4. Water Uptake of the Films. Gamma treated (100 krad) films of chitosan, gelatin, and blend were immersed in the static water bath for $90 \mathrm{sec}$ at room temperature $\left(25^{\circ} \mathrm{C}\right)$. It is

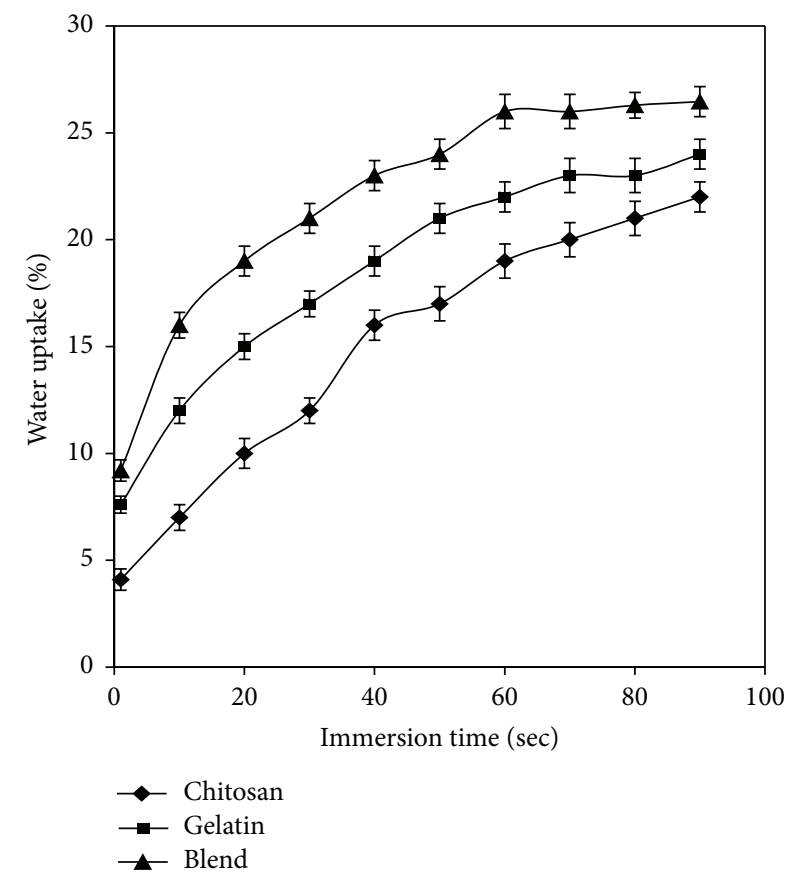

FIGURE 7: Water uptake of the films of gamma treated (100 krad) chitosan, gelatin, and blend.

to be noted here that this dose of gamma radiation performed the best mechanical properties over the other gamma doses or UV treated films. Percentages of water uptake of the treated films of chitosan, gelatin, and blend are plotted in Figure 7. It was observed that all samples absorbed a significant amount of water up to $10 \mathrm{sec}$, then continue to absorb, and became almost to plateau with time. For $90 \mathrm{sec}$ duration, films of chitosan, gelatin, and blend absorbed 22, 24, and 28\% of water, respectively. It is clearly mentioned that blend absorbed the highest amount of water over the chitosan or gelatin films. On the other hand, chitosan absorbed the lowest amount of water during aqueous immersion of the films.

3.5. Scanning Electron Microscopic (SEM) Analysis of the Films. Surfaces of the prepared films of chitosan, gelatin, and blend were studied by SEM and the images are given in Figure 8. From the investigation it was found that some rough surfaces appeared for chitosan which may be attributed from microbubbles formed during casting. The gelatin surface is quite good compared to that of the chitosan surface. In the blend surface, few pits are clearly evidenced and this is generated from bubbles of gelatin during casting. Gelatin has a strong tendency to form gels with a lot of bubbles and during experiment it was tried to remove all the bubbles. But some microbubbles still remained and it was not possible to remove all of the microbubbles. From the SEM of blend, no boundary line is found between gelatin and chitosan and it is indicated that blend between chitosan and gelatin mixed successfully.

3.6. Differential Scanning Calorimetric (DSC) Analysis of the Films. The glass transition temperature, melting temperature, and melting enthalpy of the chitosan, gelatin, and their 


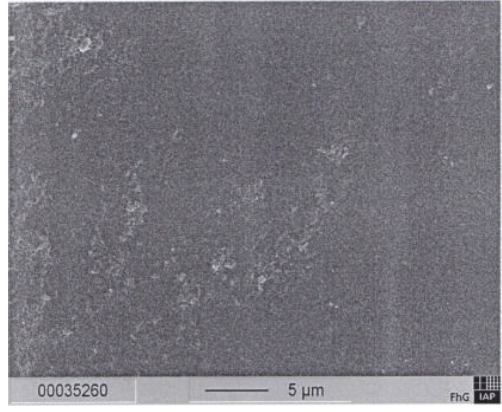

Chitosan

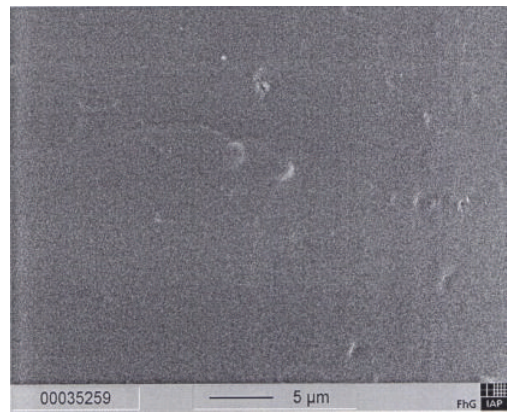

Gelatin

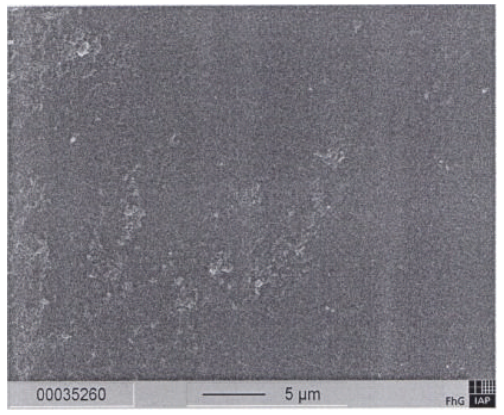

Blend

FIGURE 8: SEM images of the surface of the films of chitosan, gelatin, and blend.

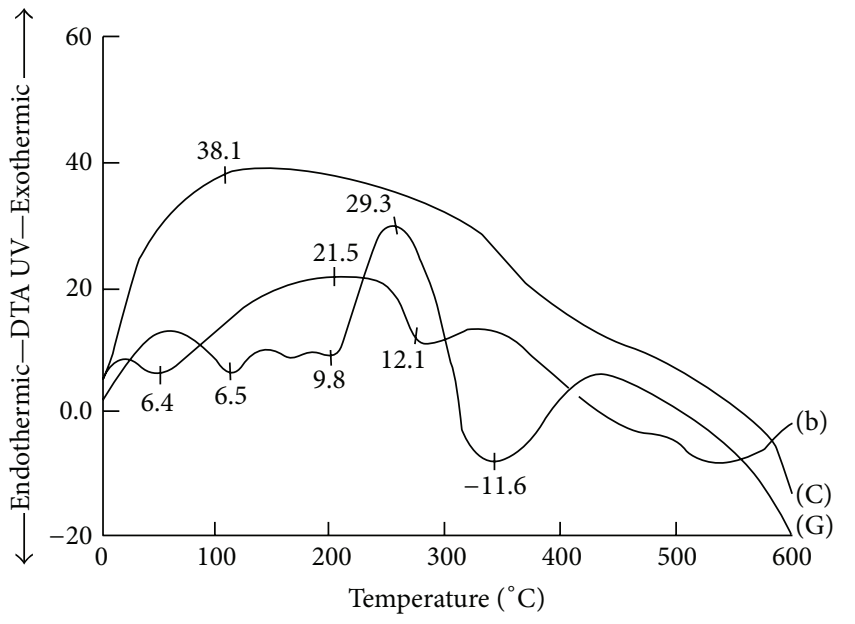

(a)

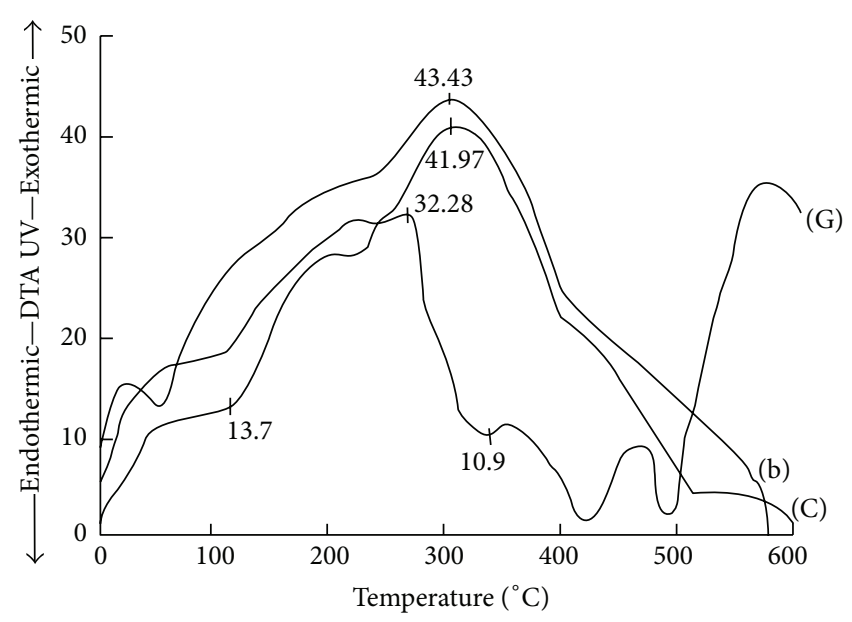

(b)

FIGURE 9: (a) DTA studies of the raw chitosan (C), gelatin (G), and their blend (b). (b) DTA studies of the irradiated chitosan (C), gelatin $(\mathrm{G})$, and their blend (b).

blend were measured by using DTA technique. Figure 9(a) shows the first heating scan programmed from 0 to $600^{\circ} \mathrm{C}$ at a heating rate of $10^{\circ} \mathrm{C} / \mathrm{min}$. The midpoint of the specific heat change associated with the glass transition was taken as the glass transition temperature $\left(T_{q}\right)$ and the peak temperature of the melting endotherm was taken as the melting temperature $\left(T_{m}\right)$ of the transition. The area underneath the endotherm divided by the total sample weight $(\Delta H /$ gelatin, $\mathrm{j} / \mathrm{g})$ indicates the percentage of structural order in the gelatin.

From Figure 9(a), for raw gelatin $(\mathrm{G}), T_{m}$ value is 29.3, at a temperature range between $250^{\circ} \mathrm{C}$ and $300^{\circ} \mathrm{C}$, for raw chitosan film (C), $T_{m}$ value is 38.1, and for blend (b), $T_{m}$ value is 21.5 , where, from Figure 9(b), it is clearly shown that $T_{m}$ value increased in every case, whereas, from Figure 10(b), it is clearly shown that $T_{m}$ value increased in every case. Gamma irradiated gelatin shows endothermic peak at $250^{\circ} \mathrm{C}-300^{\circ} \mathrm{C}$ and $T_{m}$ value is $32.28,41.97$ for irradiated chitosan film (C), and 43.43 for irradiated blend.

3.7. Thermogravimetric Analysis (TGA Analysis). Figures 10(a) and 10(b) show the TGA traces for raw samples and irradiated samples. From Figure 10(a), it is clearly observed that for all three samples, raw gelatin $(\mathrm{G})$, raw chitosan (C), and raw chitosan-gelatin blend (b), the water content decreases continuously in two zones. The first weight loss approximately at $50^{\circ} \mathrm{C}-100^{\circ} \mathrm{C}$ was due to the loss of water; the second weight loss of water started at about $260^{\circ} \mathrm{C}$, showing that different extent of thermal degradation of gelatin took place. From Figure 10(b), for irradiated gelatin, chitosan, and blend of chitosan-gelatin films, water content decreases in two zones. The first weight loss was at $70^{\circ} \mathrm{C}-130^{\circ} \mathrm{C}$ and second loss was at $270^{\circ} \mathrm{C}-350^{\circ} \mathrm{C}$.

3.8. X-Ray Diffraction (XRD) Studies. Figure 11 showed the XRD spectra of raw and irradiated gelatin films. Raw gelatin (A) sample showed critical change in crystallinity in comparison with the irradiated gelatin (B) sample of the same ratios. However, it is clear that sharper peaks (increased crystal size) were obtained from the gamma irradiated gelatin sample at $10^{\circ}(2 \theta)$ and $30^{\circ}(2 \theta)$. Figure 12 showed XRD spectra of chitosan with more than one crystalline peak, at $10^{\circ}(2 \theta)$ and $30^{\circ}(2 \theta)$. In the case of gamma irradiated chitosan, there was 


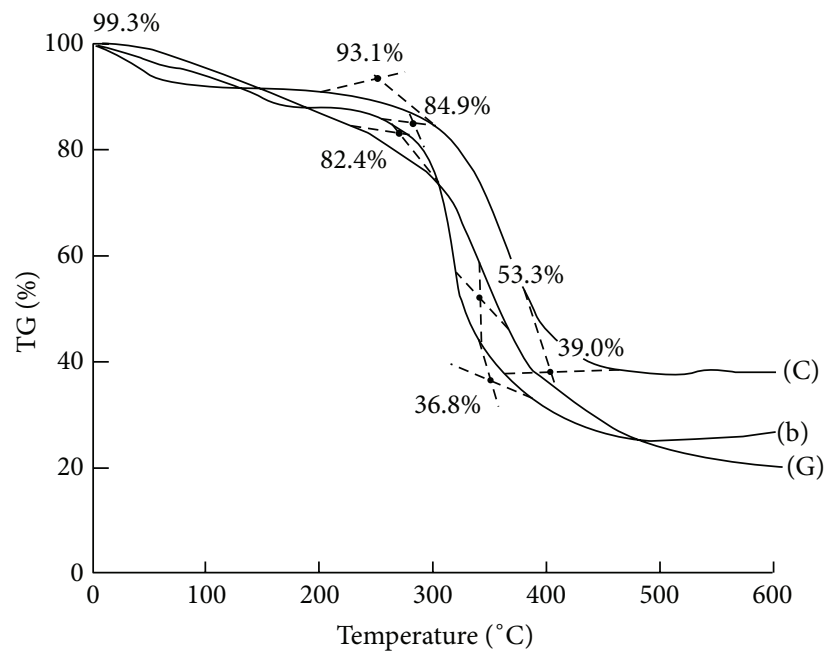

(a)

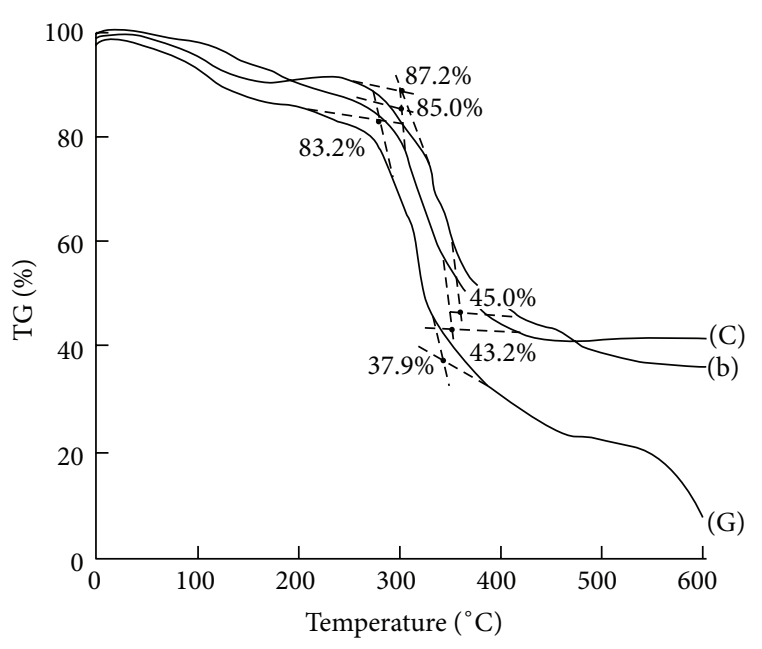

(b)

Figure 10: (a) TG\% studies of the raw chitosan (C), gelatin (G), and their blend (b). (b) TG\% studies of the irradiated chitosan (C), gelatin $(\mathrm{G})$, and their blend (b).
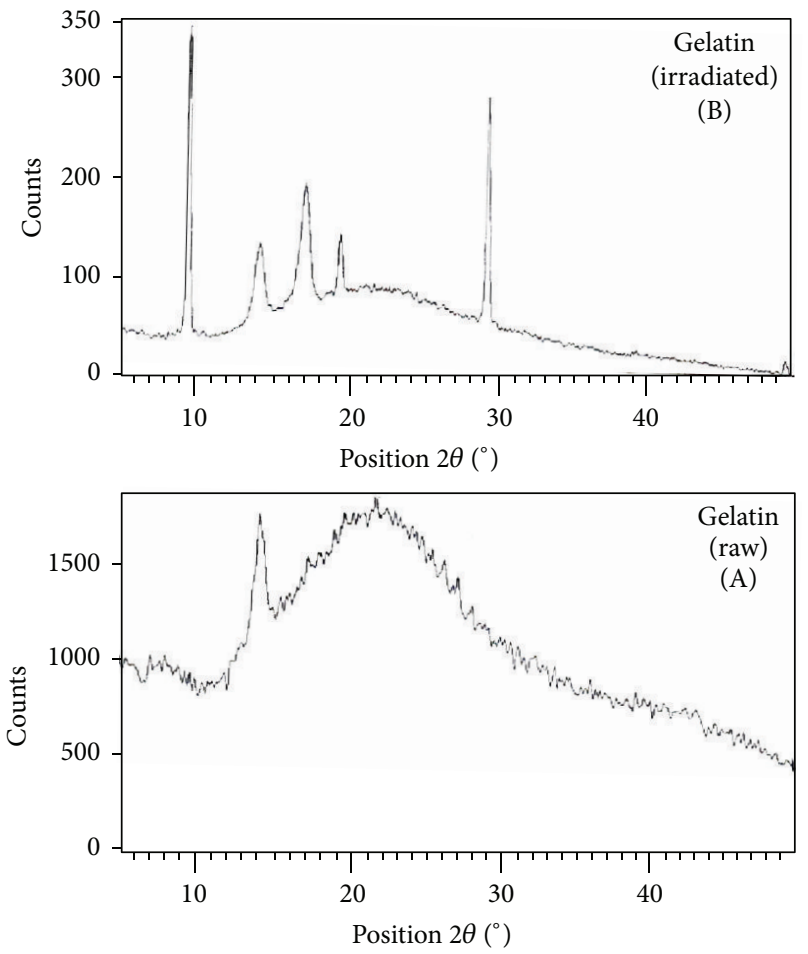

FIGURE 11: XRD studies of the raw (A) and irradiated (B) gelatin (G).

significant decrease in the intensity of characteristic peaks of chitosan [30]. The distinct differences in the diffraction patterns of raw chitosan (A) and irradiated chitosan (B) could be attributed to modification in the arrangement of molecules in the crystal lattice. In irradiated chitosan more suppressed peaks from $10^{\circ}(2 \theta)$ and $30^{\circ}(2 \theta)$ were observed, which might be due to amorphization.
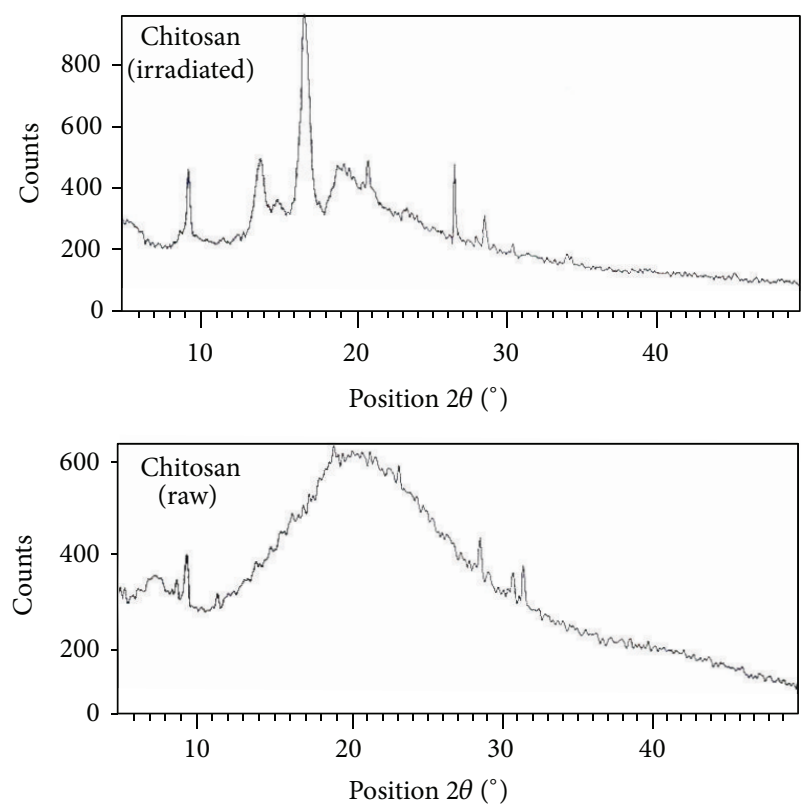

FIGURE 12: XRD studies of the raw (A) and irradiated (B) chitosan (C).

Figure 13 showed the XRD spectra of raw and irradiated blends of chitosan and gelatin film. In case of raw blend film (A), it showed two prominent crystalline peaks at $10^{\circ}(2 \theta)$ and $20^{\circ}(2 \theta)$. But in case of irradiated blend film (B), there was a significant decrease in the intensity of characteristic peaks at $10^{\circ}(2 \theta)$ and $20^{\circ}(2 \theta)$. But a single peak was found at $18^{\circ}(2 \theta)$ and then suppressed peaks were observed, which might be due to amorphization.

3.9. Fourier Transform Infrared (FTIR) Study. FTIR is of importance in the study of the molecular structure. The width 

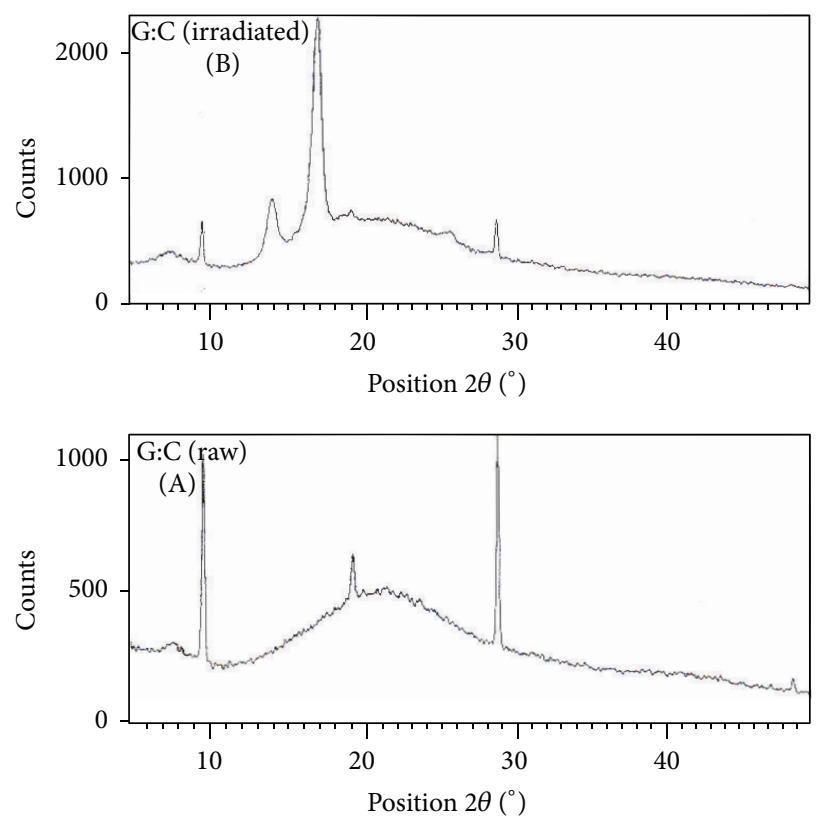

FiguRE 13: XRD studies of the raw (A) and irradiated (B) chitosan-gelatin blend (b).

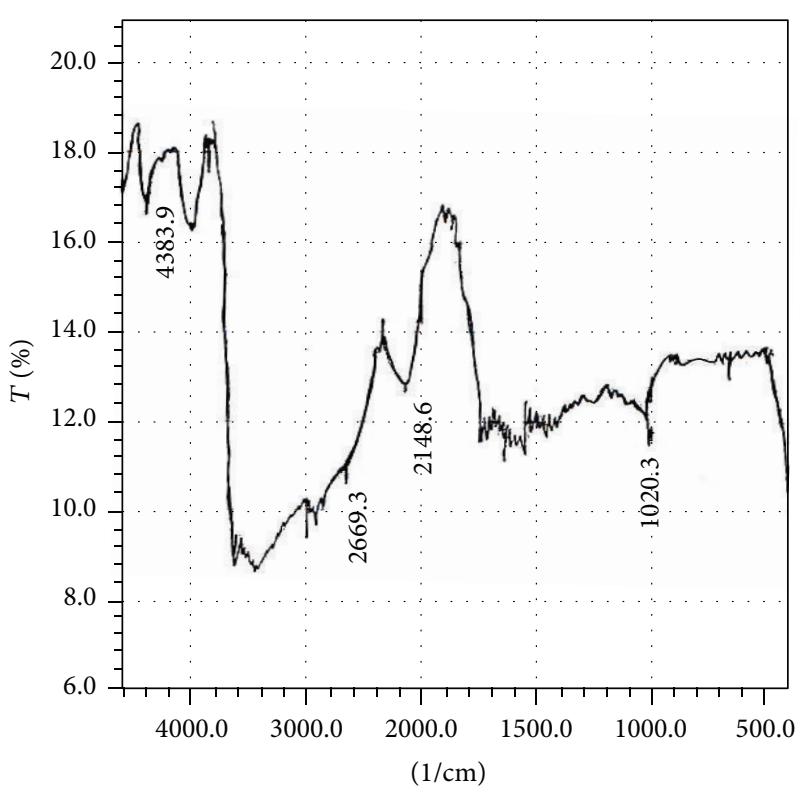

FIGURE 14: FTIR studies of the irradiated chitosan-gelatin blend (b).

and intensity of the spectrum bands, as well as the position of the peaks, are all sensitive to environment changes and to the conformation to the macromolecules on the molecular level. Intermolecular interaction occurs when different polymers are compatible, so that the FTIR spectrum of the blend is different from those of pure polymers, which is advantageous to the study extent of polymer compatibility. The FTIR spectrum of gamma irradiated films of chitosan-gelatin blend is shown in Figure 14. A characteristic band at $4383.9 \mathrm{~cm}^{-1}$ is attributed to $-\mathrm{NH}_{2}$ and $-\mathrm{OH}$ groups stretching vibration and the band for amine group at $2669.3 \mathrm{~cm}^{-1}$ is seen in the infrared spectrum of chitosan-gelatin blend.

Another major absorption band observed between $1220 \mathrm{~cm}^{-1}$ and $1020 \mathrm{~cm}^{-1}$ represents the free amino group $\left(\mathrm{NH}_{3}{ }^{+}\right)$at $\mathrm{C} 2$ of glucosamine, a major group present in chitosan [31].

\section{Conclusions}

Films of chitosan, gelatin, and their blend (chitosan and gelatin ratio was $1: 3, w / w$ ) were prepared by casting and mechanical properties were evaluated. It was investigated to find out the effect of UV and gamma radiation on the mechanical properties of chitosan, gelatin, and their blend. From this investigation, it can be concluded that both UV and gamma radiations are effective in improving the mechanical properties of chitosan, gelatin, and their blend. Comparing both types of radiation, gamma radiation found more potential than that of UV radiation. TS of gamma treated blend is $49 \mathrm{Krad}$ and $\mathrm{Eb} \%$ is $21 \%$. The thermomechanical properties have been drastically improved for gamma treated (100 Krad) films. Water uptake values became almost static after $70 \mathrm{sec}$ of immersing in aqueous media. Scanning electron microscopic analysis revealed that the blend was mixed homogenously. DSC and TGA studies were performed to understand the behavior of both of raw and irradiated films on application of thermal energy. Characterization of irradiated chitosan film, gelatin film, and blend of chitosan-gelatin film by XRD provided the evidence of reduction in hydrophilicity. FTIR of chitosan-gelatin blend is also studied. X-ray diffractograms of irradiated blend films showed the highest integrated intensity. The experimental results showed that the blend films exhibit higher thermal stability and improved mechanical properties in dry state, which suggests the occurrence of interaction 


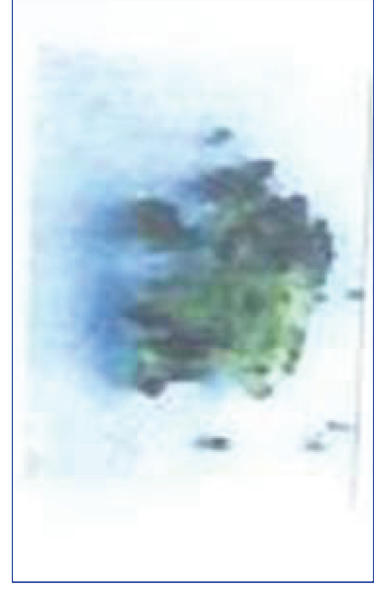

(a)

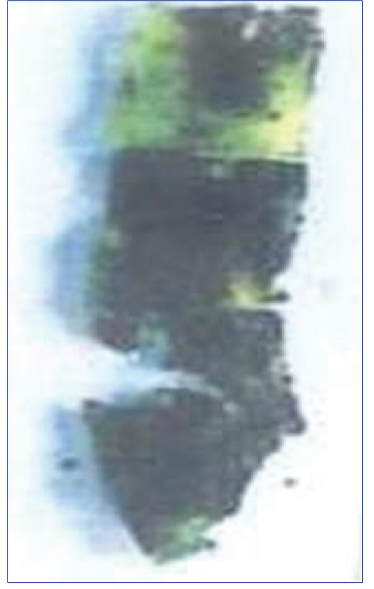

(b)

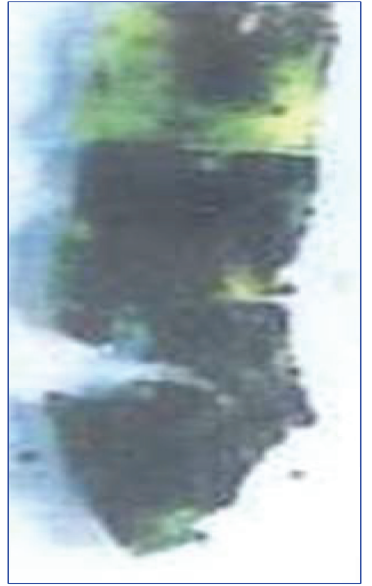

(c)

FIGURE 15: Biodegradability tests (after 24 hours in soil) of the nonirradiated gelatin (a), gamma treated (100 krad) gelatin (b), and UV treated (10 passes) gelatin films (c).

detected by XRD. The experimental results showed that the blend films (100 Krad) exhibit higher thermal stability and improved mechanical properties.

\section{Conflict of Interests}

The authors declare that there is no conflict of interests regarding the publication of this paper.

\section{References}

[1] F. Qian, F. Cui, J. Ding, C. Tang, and C. Yin, "Chitosan graft copolymer nanoparticles for oral protein drug delivery: preparation and characterization," Biomacromolecules, vol. 7, no. 10, pp. 2722-2727, 2006.

[2] Y. Hong, Z. Mao, H. Wang, C. Gao, and J. Shen, "Covalently crosslinked chitosan hydrogel formed at neutral $\mathrm{pH}$ and body temperature," Journal of Biomedical Materials Research Part A, vol. 79, no. 4, pp. 913-922, 2006.

[3] R. A. A. Muzzarelli, Chitin, Pergamon Press, New York, NY, USA, 1977.

[4] G. A. F. Roberts, Chitin Chemistry, MacMillan Press, Houndmills, UK, 1992.

[5] M. Sugimoto, M. Morimoto, H. Sashiwa, H. Saimoto, and Y. Shigemasa, "Preparation and characterization of water-soluble chitin and chitosan derivatives," Carbohydrate Polymers, vol. 36, no. 1, pp. 49-59, 1998.

[6] L. Zhao, H. Mitomo, N. Nagasawa, F. Yoshii, and K. Tmikazu, "Radiation induced degradation of carboxymethylated chitosan on aqueous solution," Carbohydrate Polymers, vol. 51, pp. 169175, 2003.

[7] R. Jayakumar, M. Prabaharan, R. L. Reis, and J. F. Mano, "Graft copolymerized chitosan-present status and applications," Carbohydrate Polymers, vol. 62, no. 2, pp. 142-158, 2005.

[8] M. A. Khan, S. Ferdous, and A. I. Mustafa, "Improvement of physico-mechanical properties of chitosan films by photocuring with acrylic monomers," Journal of Polymers and the Environment, vol. 13, no. 2, pp. 193-201, 2005.
[9] S. Ferdous, A. I. Mustafa, and M. A. Khan, "Study on mechanical properties of photocured films of chitosan/PVA and PEO/PVA blend with acrylic monomers," Journal of Macromolecular Science Part A: Pure and Applied Chemistry, vol. 40, no. 8, pp. 817-832, 2003.

[10] L. Huang, M. Zhai, J. Peng, J. Li, and G. Wei, "Radiationinduced degradation of carboxymethylated chitosan in aqueous solution," Carbohydrate Polymers, vol. 67, no. 3, pp. 305-312, 2007.

[11] I. Kaur, R. Barsola, A. Gupta, and B. N. Misra, "Graft copolymerization of acrylonitrile and methacrylonitrile onto gelatin by mutual irradiation method," Journal of Applied Polymer Science, vol. 54, no. 8, pp. 1131-1139, 1994.

[12] M. Sivakumar, P. R. G. Radhakrishnan, and H. Kothandaraman, "Grafting of glycidyl methacrylate onto gelatin," Journal of Applied Polymer Science, vol. 43, no. 10, pp. 1789-1794, 1991.

[13] S. Matsuda, H. Iwata, N. Se, and Y. Ikada, "Bioadhesion of gelatin films crosslinked with glutaraldehyde," Journal of Biomedical Materials Research, vol. 45, no. 1, pp. 20-27, 1999.

[14] I. Arvanitoyannis, A. Nakayama, and S.-I. Aiba, "Edible films made from hydroxypropyl starch and gelatin and plasticized by polyols and water," Carbohydrate Polymers, vol. 36, no. 2-3, pp. 105-119, 1998.

[15] T. Scherzer and R. Schubert, "Oxygen permeability of electron beam cured gelatin methacrylate layers," Polymers for Advanced Technologies, vol. 9, no. 10-11, pp. 777-785, 1998.

[16] C.-M. Deng, L.-Z. He, M. Zhao, D. Yang, and Y. Liu, "Biological properties of the chitosan-gelatin sponge wound dressing," Carbohydrate Polymers, vol. 69, no. 3, pp. 583-589, 2007.

[17] C. Jo, H. Kang, N. Y. Lee, J. H. Kwon, and M. W. Byun, "Pectinand gelatin-based film: effect of gamma irradiation on the mechanical properties and biodegradation," Radiation Physics and Chemistry, vol. 72, no. 6, pp. 745-750, 2005.

[18] T. Kojima, M. Bessho, M. Furuta, S. Okuda, and M. Hara, "Characterization of biopolymer hydrogels produced by $\gamma$-ray irradiation," Radiation Physics and Chemistry, vol. 71, no. 1-2, pp. 233-236, 2004.

[19] C.-Y. Lii, P. Tomasik, H. Zaleska, S.-C. Liaw, and V. M.F. Lai, "Carboxymethyl cellulose-gelatin complexes," Carbohydrate Polymers, vol. 50, no. 1, pp. 19-26, 2002. 
[20] M. Tamada, N. Seko, and F. Yoshii, "Application of radiationgraft material for metal adsorbent and crosslinked natural polymer for healthcare product," Radiation Physics and Chemistry, vol. 71, no. 1-2, pp. 221-225, 2004.

[21] S. Kapoor and C. Gopinathan, "Reduction and aggregation of silver, copper and Cadmium ions in aqueous solutions of gelatin and carboxymethyl cellulose," Radiation Physics and Chemistry, vol. 53, no. 2, pp. 165-170, 1998.

[22] J. P. Fouassier, Photoinitiation, Photopolymerization, and Photocuring: Fundamentals and Applications, Hanser Gardner Publications, Cincinnati, Germany, 1995.

[23] A. Lagos and J. Reyes, "Grafting onto chitosan. I. Graft copolymerization of methyl methacrylate onto chitosan with Fenton's reagent $\left(\mathrm{Fe}^{2+}-\mathrm{H}_{2} \mathrm{O}_{2}\right)$ as a redox initiator," Journal of Polymer Science Part A: Polymer Chemistry, vol. 26, no. 4, pp. 985-991, 1988.

[24] B. Jansen and G. Ellinghorst, "Radiation-induced modification of polyurethane-elastomers with hydroxyethyl methacrylate," Journal of Polymer Science: Polymer Symposia, vol. 66, no. 1, pp. 465-473, 1979.

[25] B. G. Sparks and D. G. Murry, United States Patent 4,572, 906, 1986.

[26] P. Haque, A. I. Mustafa, and M. A. Khan, "Effect of crosslinking monomers on the physico-mechanical and degradation properties of photografted chitosan film," Carbohydrate Polymers, vol. 68, no. 1, pp. 109-115, 2007.

[27] P. Haque, A. I. Mustafa, and M. A. Khan, "Development and modification of ethylene glycol grafted chitosan films by photocuring," Nuclear Instruments and Methods in Physics Research Section B: Beam Interactions with Materials and Atoms, vol. 236, no. 1-4, pp. 314-317, 2005.

[28] F. Khan and S. R. Ahmad, "Graft copolymerization reaction of water-emulsified methyl methacrylate with preirradiated jute fiber," Journal of Applied Polymer Science, vol. 65, no. 3, pp. 459468, 1997.

[29] M. M. I. Khalil, N. M. El-Sawy, and G. A. El-Shobaky, "Gammairradiation effects on the thermal and structural characteristics of modified, grafted polypropylene," Journal of Applied Polymer Science, vol. 102, no. 1, pp. 506-515, 2006.

[30] Y. Wan, K. A. M. Creber, B. Peppley, and V. T. Bui, "Synthesis, characterization and ionic conductive properties of phosphorylated chitosan membranes," Macromolecular Chemistry and Physics, vol. 204, no. 5-6, pp. 850-858, 2003.

[31] K. Singh, A. K. Tiwary, and V. Rana, "Ethylenediaminediacetic acid bis(carbido amide chitosan): synthesis and evaluation as solid carrier to fabricate nanoemulsion," Carbohydrate Polymers, vol. 95, no. 1, pp. 303-314, 2013. 

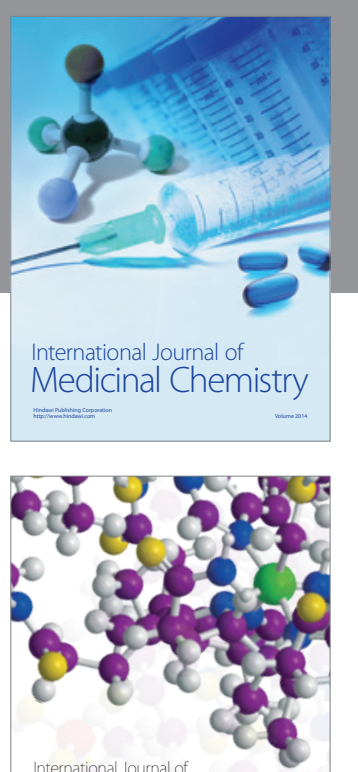

Carbohydrate Chemistry

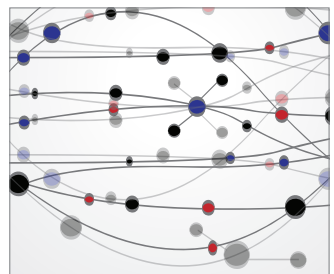

The Scientific World Journal
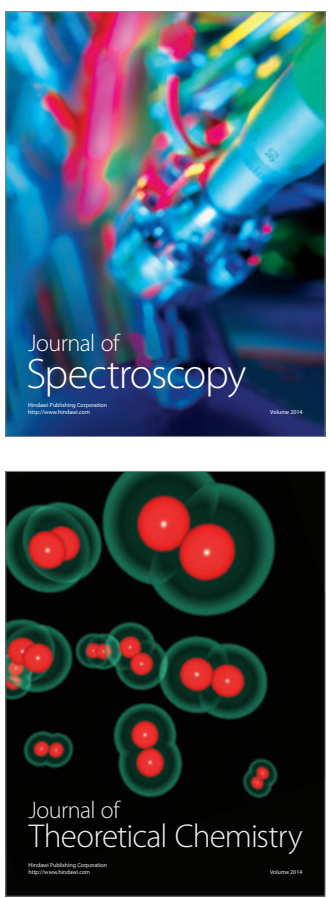
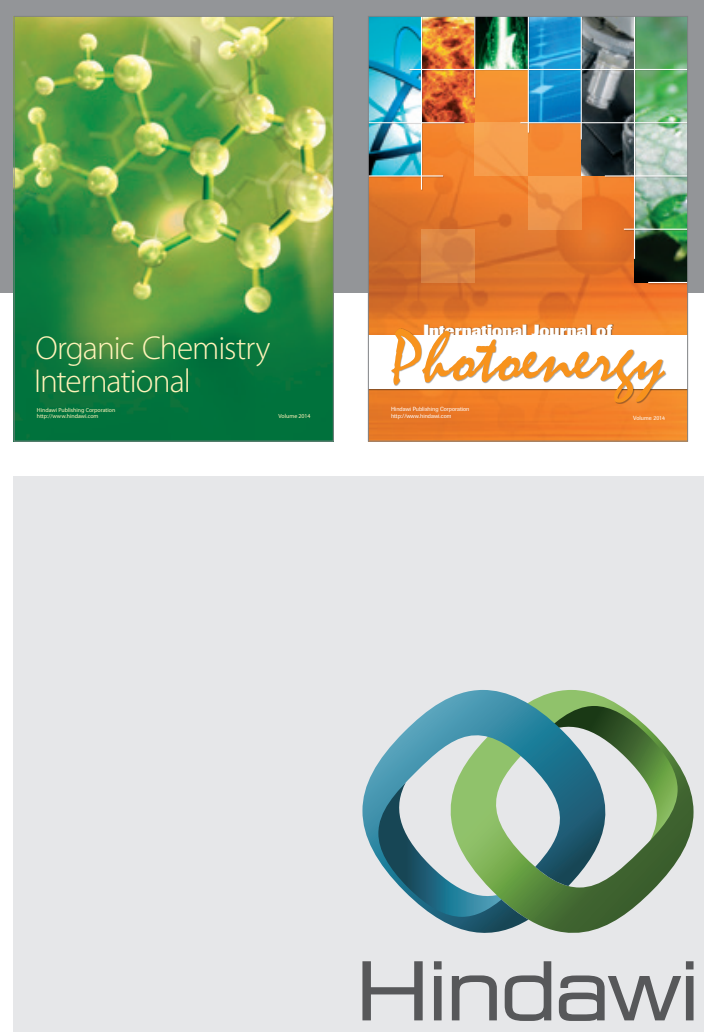

Submit your manuscripts at

http://www.hindawi.com

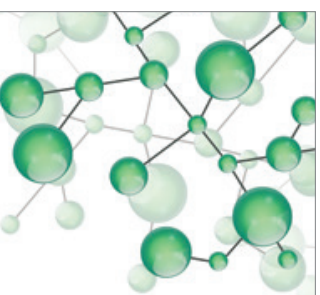

International Journal of

Inorganic Chemistry

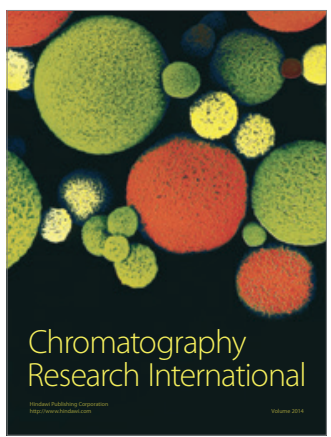

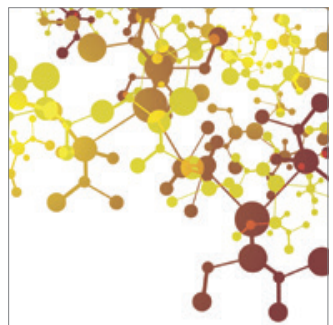

Applied Chemistry
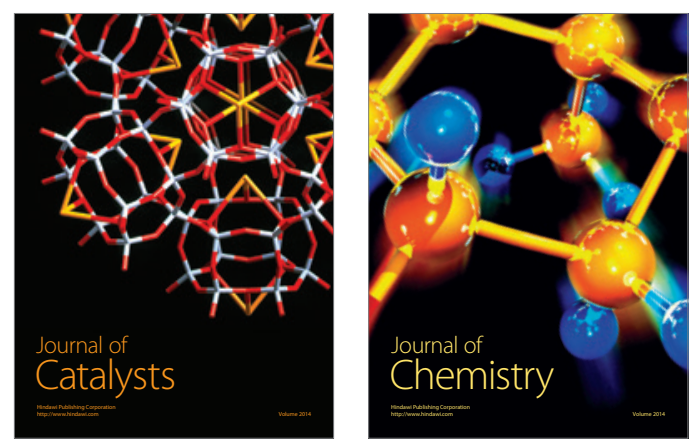
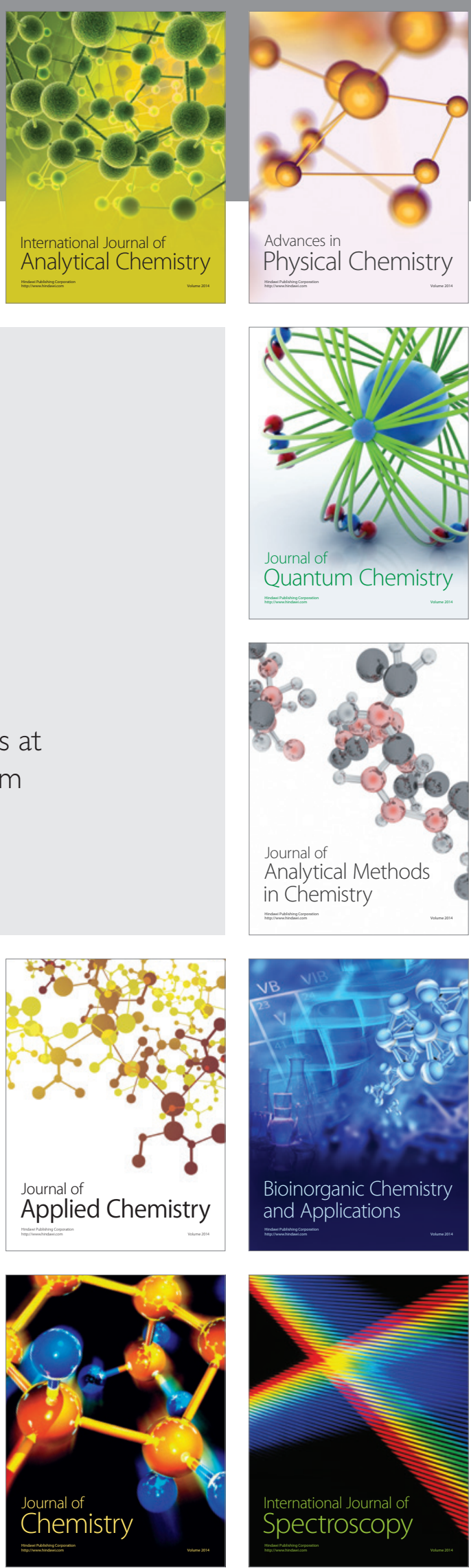